\title{
Freezing adaptability and chemical composition of Strawberry (Fragaria X ananassa Duch.) in Bangladesh
}

\author{
A. N. Chowdhury, A. Nargis, M. Z. Rahman*, A.K.M.S. Alam, M. Ibrahim and \\ S. Akhter \\ Bangladesh Council of Scientific and Industrial Research Laboratories, Rajshahi - 6206, Bangladesh.
}

\begin{abstract}
The physiological weight loss of Strawberry (Fragaria $x$ ananassa) in different media showed that in ambient temperature, 40\% sugar solution(A T) media, has the highest shelf life and it is 8 days. The pulp prepared from RABI-3 and American Festival variety can be preserved for 120 days. The composition of quality parameters were reduced very little (after 120 days) i.e. reduced amount is very low. In RABI-3, Moisture content were $37.63 \%$, TS $62.37 \%$, pH 3.21, TSS $61.8 \%$ total sugar $54.2 \%$, reducing sugar $18.01 \%$, non reducing sugar $36.19 \%$, acidity $0.218 \%$, sugar acid ratio 248.42 and vitamin C $27.35 \%$ respectably on 120 days. In American Festival variety the moisture were 39.39\%, TS 60.59\%, pH 3.00, TSS 59.1\%, total sugar $46.3 \%$, reducing sugar $15.6 \%$, non reducing sugar $30.70 \%$, acidity $0.228 \%$, sugar acid ratio 203.10 and vitamin $C 27.06$ on the effect of 120 days storage period.
\end{abstract}

Key words: American Festival variety, Fragaria x ananassa, Preservation, RABI-3, Shelf life.

\section{Introduction}

Strawberry Fragaria $x$ ananassa is one of the popular fruit of the world and very recently it has gained adaptability as well as popularity in Bangladesh. It is a highly priced fruit in all over the world Though Strawberry has introduced newly in Bangladesh but now it has evolved as a money spinning cash crop. In Bangladesh, micropropagation of strawberry played a vital role in strawberry cultivation.

Strawberries (F. ananassa) are an excellent source of vitamin C (average 40-90/100 mg), fiber, foliate, vitamin $\mathrm{K}$ and potassium [1]. Depending on age group, the daily requirement for vitamin $\mathrm{C}$ is about $60-90 \mathrm{mg}$ [2] [3], thus with a supply of $100 \mathrm{~g}$ of strawberries daily needs of vitamin $C$ will be covered [1] [4] .

Strawberries also contain substantial amounts of ellagitannins and anthocyanins, which may help treat the hyperglycemia and high blood pressure associated with type 2 diabetes; these substances have antioxidant properties that lowered cholesterol and risk of metabolic syndrome in women [5]. Strawberries contain fisting, an antioxidant that has been studied in relation of Alzheimer's disease and to kidney failure resulting from diabetes [6].

According to its nutritional and medicinal value, development of preservation technology of strawberry products, which is suitable for Bangladeshi agro-climatic condition, is an urgent need. Technical knowledge is very few for Strawberry processing [7]. For this, a research work was done for the processing and preservation of strawberry products.

\section{Materials And Methods}

Two strawberry varieties namely, RABI-3 and American Festival were used in the experiment. RABI-3 variety was developed and released by Plant Breeding and Genetic Engineering Laboratory, Department of Botany, University of Rajshahi, Bangladesh. It is very popular and commercially cultivated in Bangladesh. Fresh and ripe strawberries were harvested from the experimental field of BCSIR Laboratories, Rajshahi during October to December, 2011. The physical appearance and organoleptic tests for two varieties were conducted by a test panel consisting 5 scientists to determine the quality and acceptability of the strawberries.

Flow chart of strawberry pulp preparation method is follows 


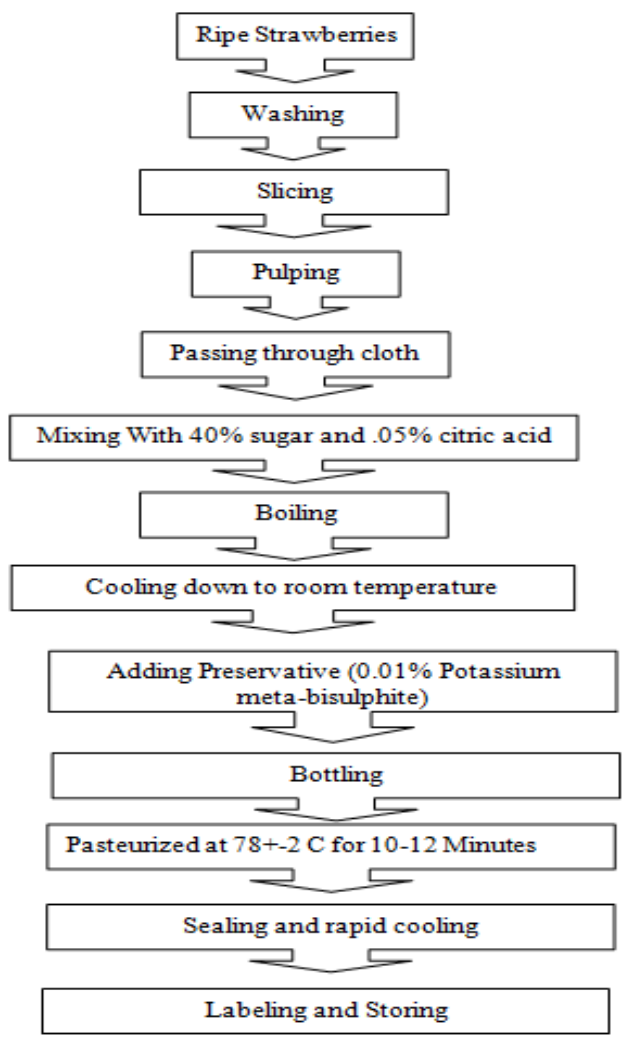

Flow chart-1. Procedure of making strawberry pulp [8].

The $\mathrm{pH}$ was determined by a $\mathrm{pH}$ meter and moisture was analyzed by the conventional procedure. Total Titrable Acidity (TTA) after Rangana [9], Total Soluble Solids (TSS) by AOAC method [10] and Vitamin-C content by Bessey and King were followed [11]. Total Sugar Content determined by anthrone method as in Jayaraman [12], reducing sugar using Dinitrosalicylic acid method described by Miller [13] and dry matter followed by Karmas [14].

\section{Results and Discussion}

The post harvest shelf life of strawberry fruit in different media was studied and results were presented in Tabel-1. It was observed that dipping in $40 \%$ sugar solution had the shelf life of 5 days in ambient temperature and above 5 days at freezing condition which is the highest among these media. On the other hand, other two media showed shelf life of 5 days when stored at freezing condition but less than 5 days at ambient temperature.

The overall quality of these two varieties was evaluated by the test panel (Table-2). It was observed that the qualities of RABI-3 variety were better and more preferred than the other variety. However, American festival was not in inferior than RABI-3 at any respect more over its color was more attractive than RABI-3 variety.

Strawberry pulp from two varieties was formulated, processed and stored for 120 days at ambient temperature $\left(22-37^{\circ} \mathrm{C}\right)$ to assess their suitability for preservation. The effect of storage on the composition and acceptability was also evaluated at different intervals and the results are presented in Table-3.

Strawberry pulp prepared from both varieties possessed an attractive color. A slight variation in color was observed between the two prepared products. The observed color variation was due to the varietal variation. During storage of the pulp of RABI-3 total soluble solids (TSS) was increased but the rate was found to be very low.

From the first day to 120 days, acidity increased slowly from 0.215 to 0.218 in RABI 3 and 0.225 to 0.228 in American Festival verities. However, up to $3^{\text {rd }}$ day acidity remained constant $(0.215$ and 0.225 respectively in RABI 3 and American festival). Then it was increased slowly and remained constant ( 0.216 and 0.226 ) up to 20 days. It increased again and rose up to 0.217 and 0.227 and remained constant for 60 days. Finally, from $90^{\text {th }}$ day the acidity started to rise and remained constant $(0.218$ and 0.228$)$ up to 120 days.

Incase of pulp of RABI-3 variety the rate of decreasing of moisture was lower (from 37.65 to 37.63) that is $0.0531 \%$ but in case of American Festival variety this rate was higher than RABI-3 variety (from 39.43 to 39.39 ) that is $0.1014 \%$. $\mathrm{pH}$ of the pulp decreased in both varieties, but in case of RABI-3 decreasing of $\mathrm{pH}$ was 
lower than (from 3.25 to 3.21;) American Festival (from 3.05 to 3.00; 0.05). In case of RABI-3 the amount of vitamin $\mathrm{C}$ was decreased gradually (63.52 at o days to 27.35 at 120 days). The decreased amount is 36.17 or $56.94 \%$ on the other hand amount of vitamin C in American Festival variety was also decreased (62.12 at o day to 27.06 or at 120 days) gradually. The decreased amount is 35.06 or $56.43 \%$. So it can be said that after storage of 120 days the amount of reduced vitamin $\mathrm{C}$ in the pulp of both varieties were or less same.

Total sugar was reduced in pulp of both varieties. The RABI-3 variety showed the decrease of total sugar from 54.5 at o day to 54.2 at 120 days, so the reduced amount was 0.3 .But in case of American Festival total sugar was reduced from 46.8 at o day to 46.3 at 120 days. So the reduced amount was 0.5 . So it can be said that the reduced amount of total sugar after 120 days storage period is lower at RABI-3 than American Festival. The sugar acid ratio of pulp prepared from RABI-3 variety was reduced from 253.49(at o day) to 248.42 (at 120 days) so the reduced amount was 5.07. But the sugar acid ratio of pulp prepared from American Festival variety was also reduced from 208.00 (at o day) to 203.10 (at 120 days). So the reduced amount was 4.90 that is lower than that of RABI-3 variety.

Fruits stored at $3{ }^{\circ} \mathrm{C}$ in air or in $5,10,15$ and $20 \% \mathrm{CO}_{2}$ remained in good condition for 10 days, and all conditions of $\mathrm{CO}_{2}$ reduced rotting due to Botrytis. The alcohol content of the fruit increased with the length of storage and higher concentration of $\mathrm{CO}_{2}$ [15]. At $6^{\circ} \mathrm{C}$ regardless of the treatment, fruit quality could not be preserved for more than 7 days [16]. Hansen and Bohling reported that $20-30 \% \mathrm{CO}_{2}$ inhibited respiration and arrested decay for several days but $50 \% \mathrm{CO}_{2}$ resulted in the development of off-flavor [17].

The study of quality parameters of preserved strawberry pulp at different intervals revels that the pulp prepared from RABI-3 and American Festival variety can be preserved for 120 days. Here the composition of quality parameters were reduced very little (after 120 days) i.e. reduced amount is very low. From the comparative study quality parameters of two preserve strawberry pulps, it is clear that RABI-3 variety is more suitable than the pulp of American Festival variety, though they showed nearly equal results.

After storage of 120 days the amount of Vitamin C reduced in the pulp of both varieties. The results of Ayub et $a l$ also indicated that storage period and temperature had significant effect on ascorbic acid content of different samples [18]. There was a gradual decrease in vitamin C of strawberry juice. Ascorbic acid is the most difficult vitamin of be preserved during pasteurization. As it is the least stable vitamin in the product during storage. In a similar study Viberg et al reported a decrease in ascorbic acid during they recorded that ascorbic acid in strawberry pulp were affected after treatment involving freezing, heating and accelerated storage [19]. These results are in agreement with the findings of Nunes et. al. [20], who recorded a change in Chandler variety of strawberries stored at $4^{\circ} \mathrm{C}$.

In these studies, acidity of both varieties pulps increased. The increase of acidity might be due to hydrolysis of sugar into sucrose and fructose with subsequent fermentation to alcohol and formation of organic acids etc. Microorganisms might be responsible for causing these changes [21]. The findings of Ayub et al suggest that storage intervals and treatments had a significant effect on acid content of juice content during storage [18]. These results are in agreement with the findings of Nunes et al. [22], who reported an increase if acidity during storage. This increase might be due to the break down of pectin in to pectin acid. The results were confirmed by the findings of Koyuncu and Dilmacunal [23].

According to Table 3(a) and 3 (b) the $\mathrm{pH}$ of the pulp was decreased in both materials and gradual increase in TSS and non reducing sugar has decreased during four months storage of pulp.

Ayub et al suggests total storage intervals and fragment had a significant effect on acid content of $\mathrm{pH}$ content during storage [18]. He found reduced $\mathrm{pH}$ values during storage period. Similar results were recorded by Ali who reported that acidity in fruit juices increases and $\mathrm{pH}$ decrease during processing and storage [24]. Ayub et $a l$ also showed that different treatments and storage intervals had a significant affect on TSS of strawberry juice. This result is also similar to our findings [18].

Sugars are the most important constituent of fruit product and are essential factor for the flavor of the food product and also act as a natural food preservative. Results of Ayub et al showed that reducing sucrose has increased in their product during three months of storage [18]. These results are in agreement with Ruiz-Nieto et al [25] who showed an increase in glucose and fructose contents in strawberry fruits. These results are similar with our findings during storage life of pulps for four months.

Ayub et al found that non reducing sucrose decreased in all his samples of strawberry juice in different conditions and during storage life [18]. The storage and treatments had a significant affect on non reducing sucrose of strawberry juice stored at refrigeration temperature. These results are confirmed by Ruíz-Nieto et al [25] who suggested that sucrose content of the convert to glucose and fructose during the storage results in the change in sucrose contents of juices. In this work non reducing sugar has also decreased during four months storage life of pulps. 


\section{Conclusion}

This study on preservation technology of strawberry pulp will help the growers and also local fruit industries which can reduce the post harvest losses and thus it can be available to the customers all the year round, as strawberry product. It is hoped that the findings will help the beverage industries to utilize this fruit for product preparation with increased shelf stability and consumer demand.

\section{Acknowledgment}

The authors express their gratitude to Dr. Zahurul Haque, Director, BCSIR Laboratories, Rajshahi for providing all research facilities. The authors also express their sincere thanks to Chairman, BCSIR for his kind co-operation.

\section{REFERENCES}

[1] C.A. Lundergan, and I.N. Moore, Variability in vitamin C content and color of strawberries in Arkansas, Arkansas Farm Research, 24, 1975, 2

[2] L.M. Ausman. and J. Mayer, Criteria and recommendations for vitamin C intake, Nutrition Reviews, 57, 1999, $222-224$

[3] DRI, Dietary Reference Intakes for Vitamin C, Vitamin E, Selenium and Carotenoids, 2000. Retrieved from http:/www.iom.edu/ /media/Files/Activity\%20Files/Nutrition/DRIs/DRI Vitamins.pdf

[4] McCance and Widdowson. The Composition of Foods, 4th Edition. (Cambridge: Royal Society of Chemistry, 1978)

[5] P.M. Da Silva, J.E. de Carvalho, F.M. Lajolo, M.I. Genovese and K. Shetty, Evaluation of Antiproliferative, Anti-Type 2 Diabetes, and Antihypertension Potentials of Ellagitannins from Strawberries (Fragaria $\times$ ananassa Duch.) Using In Vitro Models, Journal of Medicinal Food, 13(5), 2010, 1027-1035.

[6] F. Giampieri, S. Tulipani, J.M. Alvarez-Suarez, J.L. Quiles, B. Mezzetti, and M. Batthino, The Strawberry: Composition, nutritional quality and impact on human health, Nutrition J. 28(1), 2012, 9-19.

[7] H. Imran, Strawberry Project, Faculty of Business Administration. University of Rajshahi. Bangladesh. P.1. (2010)

[8] M. Zhang, G. Xiao, J. Peng, and V.M. Salokhe, Effects of Single and Combined Atmosphere Packages on Preservation of Strawberries, International Journal of Food Engineering, 1(4), 2005.

[9] S. Rangana, Handbook of Analysis and quality control for Fruit and Vegetable products (New Delhi: Tata McGraw-Hill Publishing Company Ltd., 1986).

[10] AOAC, Official methods of Analysis of the Association of Official Analytical Chemists, (15th ed. pp. 1058-1059.1984.)

[11] O.A. Bessey and C.G. King, The distribution of vitamin C in plant and animal tissues and its determination, J. Biol. Chem, 103, 1933, 687-698.

[12] J. Jayarman, Laboratory Manual in Biochemistry (New Delhi: New age International Lit., 1981).

[13] G.L. Miller, Use of dinitrosalicylic acid reagent for determination of reducing sugar, Anal. Chem., 31(3), 1959, 426- 428.

[14] E. Karmas, Techniques for measurement of moisture content of foods, Food Technology, 34, 1980, 52.

[15] S.K. Mitra, D.S. Rathore, and T.K. Bose, Temperate fruit, (India: Horticulture and Allied Publishers, 1991).

[16] W. Płocharski, E. Lange and W. Lenartowicz,. PART II Changes in strawberry quality in relation to storage conditions. Fruit Sci. Rep. 5, 2, 1978.

[17] H. Hansen, and H. Bohling, Long-term storage of Chinese cabbage, Acta Horticulturae, 116, 1981, 31-34.

[18] M. Ayub, J. Ullah, , M. Ali, and Z. Alam, Evaluation of Strawberry Juice Preserved with chemical Preservatives at Refrigeration Temperature, International Journal of Metabolism, 2(2), 2010, 27-32.

[19] U. Viberg, C. Alklint, , B. Akesson, G. Onning, , I. Sjohom, I.T. Kumpullainen, and J.T. Salonen, The effect of processing on total antioxidative capacity in strawberries, In J.T. Kumpulainen and J.T. Salonen, (Eds) Natural antioxidants and anticarcinogens in nutrition, health and disease (England: Woodhead Publishing Ltd., 1999)

[20] M.C.N. Nunes, J.K. Brecht, M.B. Morais, and S.A. Sargent, Physical and chemical quality characteristics of strawberries after storage are reduced by a short delay to cooling. Post harvest Biology and Technology. 6, 1995a, 17-28.

[21] W.C. Frazier and D.C. Westhoff, Food Microbiology (New York: Hill Publishing Co.,1978)

[22] M.C.N. Nunes, M.B. Morais, J.K. Brecht, and S.A. Sargent, Quality of strawberries after storage in controlled atmosphere at above optimum storage temperatures, Proceedings of the Florida state Horticulture Society.108, 1995b, 273-278.

[23] M. A. Koyuncu, and T. Dilmacunal, Determination of Vitamin C and Organic Acid Changes in Strawberry by HPLC during Cold Storage, Notulae Botanicae Horti AgrobotaniciCluj-Napoca 38(3), 2010, 95-98.

[24] M. Ali, Canning of fruits and vegetables and their juices. Effect of canning quality of juice from different varieties of oranges. M.Sc. (Ag) diss., Agricultural University. Faisalabad, Pakistan. 1965.

[25] A. Ruíz-Nieto, J.M. López-Aranda, R. López-Montero, J. López-Medina and J.J. Medina, Analysis of sugars from strawberry cultivars of commercial interest - contents evolution, Acta Hort. 439, 1997, 663-668.

Table -1. The Effect of different sugar concentration on the shelf life of strawberry fruit.

\begin{tabular}{|c|c|c|c|c|c|c|c|}
\hline \multirow[b]{2}{*}{$\operatorname{SI} N^{0}$} & \multirow[b]{2}{*}{$\begin{array}{c}\text { Sugar solution } \\
\%\end{array}$} & \multirow[b]{2}{*}{ Temperature } & \multicolumn{5}{|c|}{ Physiological Weight Loss } \\
\hline & & & $\begin{array}{c}\text { Day-1 } \\
\%\end{array}$ & $\begin{array}{c}\text { Day-2 } \\
\%\end{array}$ & $\begin{array}{c}\text { Day-3 } \\
\%\end{array}$ & $\begin{array}{c}\text { Day-4 } \\
\%\end{array}$ & $\begin{array}{c}\text { Day-5 } \\
\%\end{array}$ \\
\hline 1. & 25 & $\mathrm{~A} \mathrm{T*}$ & 100 & 85 & 65 & 55 & 50 \\
\hline 2. & & $\mathrm{FC}^{*}$ & 100 & 82 & 62 & 52 & 47 \\
\hline 3. & & A T & 100 & 90 & 70 & 60 & 55 \\
\hline 4. & 30 & $\mathrm{FC}$ & 100 & 88 & 68 & 58 & 53 \\
\hline 5 & & A T & 100 & 95 & 75 & 65 & 60 \\
\hline 6. & 35 & $\mathrm{FC}$ & 100 & 94 & 73 & 62 & 54 \\
\hline 7. & & AT & 100 & 100 & 80 & 75 & 68 \\
\hline 8. & 40 & $\mathrm{FC}$ & 100 & 100 & 100 & 100 & 100 \\
\hline 7. & & $\mathrm{~A} \mathrm{~T}$ & 100 & 70 & 40 & 20 & - \\
\hline 9. & Control & $\mathrm{F} \mathrm{C}$ & 100 & 80 & 60 & 40 & - \\
\hline
\end{tabular}


$\mathrm{AT}=$ Ambient temperature, $\mathrm{FC}=$ Freezing Condition.

Table 2.The organoleptic test score of two strawberry varieties

\begin{tabular}{|c|c|c|c|c|c|c|c|c|c|}
\hline \multirow{2}{*}{ Features } & \multirow{2}{*}{ Varieties } & \multicolumn{5}{|c|}{ Score } & \multirow{2}{*}{$\begin{array}{l}\text { Total } \\
\text { score }\end{array}$} & \multirow{2}{*}{ Mean } & \multirow{2}{*}{ Rating } \\
\hline & & 01 & 02 & 03 & 04 & 05 & & & \\
\hline \multirow{2}{*}{ Appearance } & RB* & 85 & 80 & 81 & 78 & 77 & 401 & 80.20 & Excellent \\
\hline & $\mathrm{AF}^{*}$ & 72 & 70 & 65 & 71 & 80 & 358 & 71.60 & Good \\
\hline \multirow{2}{*}{ Color } & $\mathrm{RB}$ & 74 & 70 & 78 & 80 & 75 & 377 & 75.40 & Good \\
\hline & $\mathrm{AF}$ & 80 & 78 & 85 & 81 & 87 & 411 & 82.20 & Excellent \\
\hline \multirow{2}{*}{ Flavour } & $\mathrm{RB}$ & 83 & 81 & 80 & 77 & 84 & 405 & 81.00 & Excellent \\
\hline & $\mathrm{AF}$ & 68 & 72 & 75 & 59 & 60 & 334 & 66.80 & Fair \\
\hline \multirow{2}{*}{ Taste } & $\mathrm{RB}$ & 81 & 86 & 82 & 80 & 78 & 407 & 81.40 & Excellent \\
\hline & $\mathrm{AF}$ & 60 & 67 & 70 & 72 & 68 & 337 & 67.40 & Fair \\
\hline \multirow{2}{*}{ Texture } & $\mathrm{RB}$ & 88 & 80 & 79 & 83 & 86 & 416 & 83.20 & Excellent \\
\hline & $\mathrm{AF}$ & 56 & 73 & 68 & 70 & 73 & 304 & 68.00 & Fair \\
\hline
\end{tabular}

Table 3. The effect of storage characteristics at ambient temperature on the composition of strawberry pulp.

\begin{tabular}{|c|c|c|c|c|c|c|c|c|c|c|c|c|c|c|c|c|c|c|}
\hline \multirow[b]{3}{*}{$\begin{array}{l}\text { Storage } \\
\text { Time (Day) }\end{array}$} & \multicolumn{18}{|c|}{ Name of the varieties } \\
\hline & \multicolumn{9}{|c|}{ RABI - 3} & \multicolumn{9}{|c|}{ American Festival } \\
\hline & $\mathbf{0}$ & 3 & 6 & 9 & 20 & 30 & 60 & 90 & 120 & $\mathbf{0}$ & 3 & 6 & 9 & 20 & 30 & 60 & 90 & 120 \\
\hline Moisture & 37.7 & 38 & 38 & 37.6 & 38 & 38 & 38 & 38 & 38 & 39 & 39 & 39 & 39 & 39 & 39 & 39 & 39 & 39 \\
\hline Total Solid & 62.4 & 62 & 62 & 62.4 & 62 & 62 & 62 & 62 & 62 & 61 & 61 & 61 & 61 & 61 & 61 & 61 & 61 & 61 \\
\hline $\mathrm{p}^{\mathrm{H}}$ & 3.25 & 3.3 & 3.3 & 3.23 & 3.2 & 3.2 & 3.2 & 3.2 & 3.2 & 3.1 & 3.1 & 3.1 & 3 & 3 & 3 & 3 & 3 & 3 \\
\hline TSS & 61.5 & 62 & 62 & 61.6 & 62 & 62 & 62 & 62 & 62 & 58 & 58 & 58 & 58 & 58 & 59 & 59 & 59 & 59 \\
\hline Total Sugar & 54.5 & 55 & 55 & 54.4 & 54 & 54 & 54 & 54 & 54 & 47 & 47 & 47 & 47 & 47 & 47 & 47 & 46 & 46 \\
\hline $\begin{array}{l}\text { Reducing } \\
\text { Sugar }\end{array}$ & 18.1 & 18 & 18 & 18.1 & 18 & 18 & 18 & 18 & 18 & 15 & 15 & 16 & 16 & 16 & 16 & 16 & 16 & 16 \\
\hline $\begin{array}{l}\text { Non } \\
\text { reducing } \\
\text { sugar }\end{array}$ & 36.4 & 36 & 36 & 36.3 & 36 & 36 & 36 & 36 & 36 & 31 & 31 & 31 & 31 & 31 & 31 & 31 & 31 & 31 \\
\hline Acidity & 0.22 & 0.2 & 0.2 & 0.22 & 0.2 & 0.1 & 0.2 & 0.2 & 0.2 & 0.2 & 0.2 & 0.2 & 0.2 & 0.2 & 0.2 & 0.2 & 0.2 & 0.2 \\
\hline $\begin{array}{l}\text { Sugar Acid } \\
\text { Ratio }\end{array}$ & 253 & 253 & 252 & 251 & 251 & 250 & 250 & 249 & 248 & 208 & 208 & 207 & 206 & 206 & 205 & 205 & 203 & 203 \\
\hline Vitamin C & 63.5 & 63 & 63 & 58.3 & 54 & 42 & 37 & 29 & 27 & 62 & 62 & 62 & 57 & 53 & 41 & 36 & 28 & 27 \\
\hline
\end{tabular}

